\title{
Ultrahigh surface area polypyrrole-based carbons with superior performance for hydrogen storage
}

\author{
Marta Sevilla, ${ }^{a, b}$ Robert Mokaya ${ }^{* b}$ and Antonio B. Fuertes ${ }^{* a}$ \\ Received (in $X X X, X X X) X$ th $X X X X X X X X X 200 X$, Accepted Xth XXXXXXXXX 200X \\ DOI: 10.1039/b000000x
}

Ultrahigh surface area carbons $\left(3000-3500 \mathrm{~m}^{2} \mathrm{~g}^{-1}\right)$ have been obtained via chemical activation of polypyrrole with $\mathrm{KOH}$. The carbon materials exhibit large pore volumes (up to $\sim 2.6 \mathrm{~cm}^{3} \mathrm{~g}^{-1}$ ) and possess two pore systems; one of pores in the micropore range $(\sim 1.2 \mathrm{~nm})$ and the other in the small mesopore range $(2.2-3.4 \mathrm{~nm})$. Some carbons also possess a significant proportion of $0.6 \mathrm{~nm}$ pores. Tunning of the

10 carbon textural properties was achieved through control of the activation parameters (temperature and amount of $\mathrm{KOH}$ ). The carbons achieve excellent hydrogen storage capacity of up to $7.03 \mathrm{wt} \%$ at $-196{ }^{\circ} \mathrm{C}$ and 20 bar, which is the highest ever reported for one-step activated carbons and amongst the best for any porous material. The gravimetric hydrogen uptake of the carbons translates to very attractive volumetric density of up to $37 \mathrm{~g} \mathrm{H}_{2} \mathrm{~L}^{-1}$ at 20 bar. These carbons exhibit excellent gravimetric and volumetric

15 capacities due to the fact that their high porosity is not at the detriment of packing density.

\section{Introduction}

The development of porous materials capable of storing enough hydrogen to accomplish the targets required for on-board applications (i.e., $6 \mathrm{wt}^{\%}$ and $45 \mathrm{~g} \mathrm{~L}^{-1}$ by 2010$)^{1}$ still remains a 20 challenge. For this purpose a great variety of highly porous materials such as MOFs, ${ }^{2,3}$ activated carbons, ${ }^{3-5}$ zeolites, $^{3,6}$ zeolite-like carbon materials ${ }^{7}$ and carbide-derived carbons ${ }^{5,8}$ have been investigated. In particular, carbon-based porous materials have been extensively studied as potential hydrogen stores due to 25 their high surface areas, large pore volumes, good chemical stability and the ease with which their porosity can be tailored. In this respect, the nanocasting approach constitutes a versatile route for the design of porous carbons with a pore structure suitable for hydrogen storage. Zeolites have proved to be appropriate 30 templates for the fabrication of microporous carbons with uniform micropores (size $<1 \mathrm{~nm}$ ). A hydrogen uptake of $6.9 \mathrm{wt} \%$ (at $-196{ }^{\circ} \mathrm{C}$ and 20 bar) has been reported for this type of templated carbons. ${ }^{7 \mathrm{a}}$ On the other hand, carbide-derived carbons (CDCs) also have been considered as hydrogen adsorbents taking 35 into account their large surface area (up to $2500 \mathrm{~m}^{2} \cdot \mathrm{g}^{-1}$ ) and narrow microporosity. ${ }^{9}$ In this case, the maximum hydrogen uptake measured is ca. $4.4 \mathrm{wt} \%$ (at $-196{ }^{\circ} \mathrm{C}$ and 20 bar). ${ }^{5,8}$ Recently, several studies have reported on the post-synthesis chemical or physical activation of zeolite-templated carbons or ${ }_{40} \mathrm{CDCs}$ with the aim of improving hydrogen storage capacity. $5,10,11$ Such multi-step (typically two steps) procedures can improve the hydrogen uptake by up to 96 and $63 \%$ for zeolite-templated carbon $^{11 \mathrm{a}}$ and $\mathrm{CDCs}^{11 \mathrm{~b}, \mathrm{c}}$ respectively.
Chemical activation of carbonaceous materials (i.e., coal, 45 biomass-derived products, etc) constitutes an established route for the preparation of carbons with high surface area. ${ }^{12}$ In particular, activated carbons produced using $\mathrm{KOH}$ as activating agent exhibit several attractive properties: i) a high surface areas and large pore volumes, ii) most of the porosity arises from uniform 50 micropores in the $1-2 \mathrm{~nm}$ range, iii) the pore structure can be tailored by modifying the activating parameters (i.e., activation temperature and $\mathrm{KOH} /$ carbonaceous precursor weight ratio) and iv) the activation may be performed via an easy and one-step process. ${ }^{12 \mathrm{~b}, 12 \mathrm{c}, 12 \mathrm{~d}}$ Due to these reasons, the use of one-step 55 chemically $(\mathrm{KOH})$ activated carbons for hydrogen storage has been extensively investigated. However, only moderate hydrogen uptakes $\left(3.0-5.6 \mathrm{wt} \%\right.$ at $-196{ }^{\circ} \mathrm{C}$ and various pressures) have so far been achieved for one-step $\mathrm{KOH}$ activated carbon materials. ${ }^{[4]}$ In an attempt to enhance the hydrogen storage capacity of $\mathrm{KOH}$ 60 activated carbons, Wang and co-workers, recently proposed a two-step procedure in which physical activation (with $\mathrm{CO}_{2}$ ) was followed by a chemical (KOH) activation step. ${ }^{13}$ This doubly activated carbon exhibits hydrogen uptake of up to $7.08 \mathrm{wt} \%$ at $196{ }^{\circ} \mathrm{C}$ and 20 bar. ${ }^{13}$ However, it is desirable to avoid multi-step ${ }_{65}$ activation procedures, and to date, therefore, the fabrication of chemically activated carbons with large capacity to store hydrogen, by means of simpler procedures remains an important challenge.

Several studies show that the cryogenic hydrogen storage 70 capacity of porous materials is essentially a function of surface area, and that narrow micropores $(\sim 0.7 \mathrm{~nm})$ are the most efficient hydrogen storage spaces. ${ }^{5,7,14}$ Therefore, in order to improve hydrogen adsorption capacity, activated carbons with ultrahigh 
surface area are required. Motivated by the need for suitable hydrogen stores, prepared via simpler routes, we have here selected polypyrrole as a suitable candidate to produce porous carbons with very large surface areas via a typical one-step 5 activation procedure. Polypyrrole (PPy) is an extensively studied conductive polymer that possesses a high nitrogen content and, more important, in relation to the present work, it gives a high percentage of carbonaceous residue after pyrolysis (carbon yield $\sim 60 \mathrm{wt} \%$, see Supporting Figure S1). In order to obtain highly 10 porous carbons, polypyrrole was subjected to standard chemical activation with $\mathrm{KOH}$, as described in detail in the experimental section. The pore development and chemical characteristics of the activated carbons (designated as $\mathrm{CP}-x-y$, where $x$ is the $\mathrm{KOH} / \mathrm{PPy}$ weight ratio and $y$ the activation temperature (in ${ }^{\circ} \mathrm{C}$ )) was 15 controlled via modification of the amount of activated agent used (i.e., $\mathrm{KOH} /$ polypyrrole ratio) and the activation temperature. The present work focuses not only on the impact of chemical activation on the pore development but also on the relationship between the porous characteristics of the materials and their 20 hydrogen storage capacity.

\section{Experimental}

\section{Carbon synthesis}

Polypyrrole (PPy) was prepared with the aid of $\mathrm{FeCl}_{3}$ as the oxidant. In a typical synthesis, $3 \mathrm{~g}$ of pyrrole (recently distilled 25 under nitrogen) was added to a solution of $\mathrm{FeCl}_{3}(0.5 \mathrm{M}, 200 \mathrm{~mL})$ and the mixture was magnetically stirred for $2 \mathrm{~h}$. The formed polypyrrole was separated by filtration and abundantly washed with distilled water and dried. The polypyrrole yield was close to $100 \%$. The chemical activation of polypyrrole was performed by 30 heating (at a ramp rate of $3{ }^{\circ} \mathrm{C} / \mathrm{min}$ ) a $\mathrm{KOH} / \mathrm{PPy}$ mixture (at $\mathrm{KOH} / \mathrm{PPy}$ weight ratio of 2 or 4 ) under nitrogen to a final temperature of between 600 and $850{ }^{\circ} \mathrm{C}$ for $1 \mathrm{~h}$. The activated samples were then thoroughly washed with $10 \mathrm{wt} \% \mathrm{HCl}$ to remove any inorganic salts, and then with distilled water until ${ }_{35}$ neutral $\mathrm{pH}$ and then dried in an oven at $120^{\circ} \mathrm{C}$. The carbons were denoted as $\mathrm{CP}-x-y$, where $x$ is the $\mathrm{KOH} / \mathrm{PPy}$ weight ratio and $y$ the activation temperature (in ${ }^{\circ} \mathrm{C}$ ).

\section{Characterization}

Nitrogen sorption isotherms and textural properties of the carbons 40 were determined at $-196{ }^{\circ} \mathrm{C}$ using nitrogen in a conventional volumetric technique by a Micromeritics ASAP 2020 sorptometer. The surface area was calculated using the BET method based on adsorption data in the relative pressure $(\mathrm{P} / \mathrm{Po})$ range 0.04 to 0.2 . The total pore volume was determined from the 45 amount of nitrogen adsorbed at a relative pressure of 0.99 . Micropore surface area and micropore volume were obtained via t-plot analysis. The pore size distribution (PSD) was determined via a Non Local Density Functional Theory (NLDFT) method using nitrogen adsorption data, and assuming a slit pore model. ${ }_{50}$ Scanning electron microscopy (SEM) images were obtained with a Quanta FEG650 (FEI). Transmission electron microscopy (TEM) images were taken on a JEOL (JEM-2000 FX) operating at $200 \mathrm{kV}$.
Hydrogen uptake capacity of the carbons was measured by 55 gravimetric analysis with an Intelligent Gravimetric Analyser (IGA-003 Hiden) using $99.9999 \%$ purity hydrogen additionally purified by a molecular sieve filter. The hydrogen uptake measurements were performed at $-196{ }^{\circ} \mathrm{C}$ (in a liquid nitrogen bath) over the pressure range 0 to 20 bar. The uptake data was 60 corrected for the buoyancy of the system and samples. The Helium density of the materials was measured on a gas pycnometer (AccuPyc, Micromeritics), whereas the packing density was determined by pressing a given amount of activated carbon $(\sim 0.1 \mathrm{~g})$ in a mould at a pressure of $7 \mathrm{MPa}$.

\section{${ }_{65}$ Results and discussion}

As shown in Figure 1a, the polypyrrole used as carbon precursor exhibits a sponge-like structure formed by interconnected microparticles of ca. $1 \mu \mathrm{m}$ in diameter. This morphology is highly favourable for good pore development due to the fact that it 70 provides a large interfacial area for the reaction between the polymer and the activating agent $(\mathrm{KOH})$. After the activation step, the sponge-like structure of polypyrrole is completely destroyed and the resultant porous carbon consists of irregular particles of size in the $20-100 \mu \mathrm{m}$ range that exhibit large voids 75 (Figure 1b). TEM images of the activated carbons show wormhole type porosity of uniform micro/mesopores whose size is clearly smaller for sample CP-4-600 (Figure 1c) compared to CP4-800 (Figure 1d).

The nitrogen sorption isotherms and corresponding pore size 80 distribution (PSD) curves of activated carbons prepared at temperatures of between 600 and $850{ }^{\circ} \mathrm{C}$ and a $\mathrm{KOH} /$ polypyrrole (PPy) ratio of 4 are shown in Figure $2 \mathrm{a}$ and $2 \mathrm{~b}$ respectively. Changes in the shape of the isotherms as the activation temperature rises from $600{ }^{\circ} \mathrm{C}$ to $850{ }^{\circ} \mathrm{C}$ reveal variations in the 85 porous structure of the activated carbons, and in particular an increase of the porosity in the small mesopore range. The isotherm of the sample activated at $600{ }^{\circ} \mathrm{C}(\mathrm{CP}-4-600)$ exhibits a fairly sharp 'knee' in the 0.1 to 0.3 relative pressure $(\mathrm{P} / \mathrm{Po})$ range

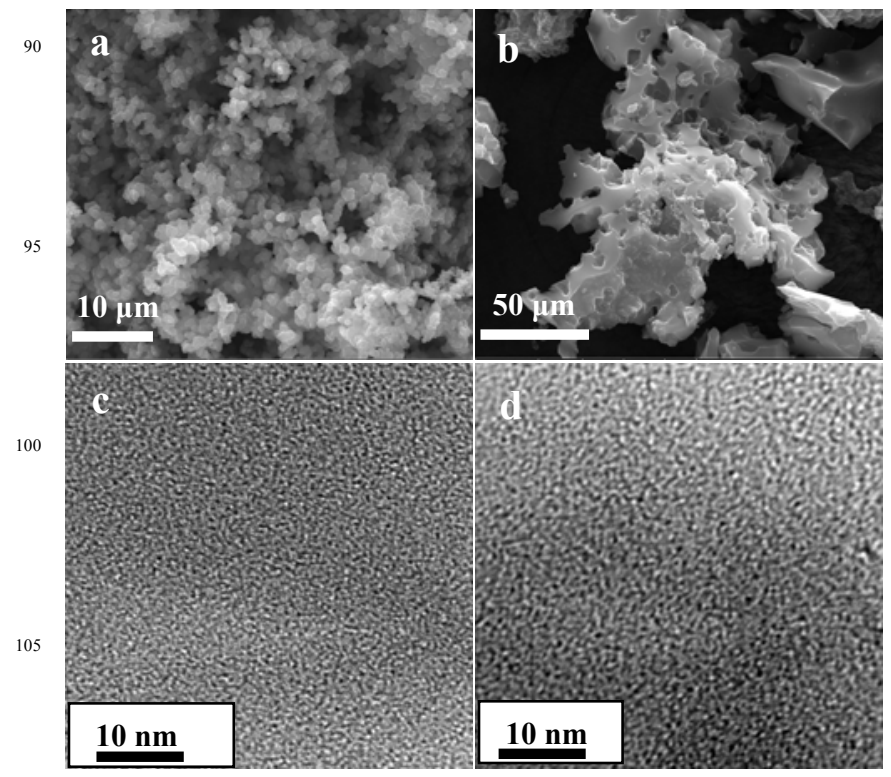

Fig. 1 SEM images of (a) polypyrrole and (b) CP-4-800, and TEM 110 images of (c) CP-4-600 and (d) CP-4-800. 

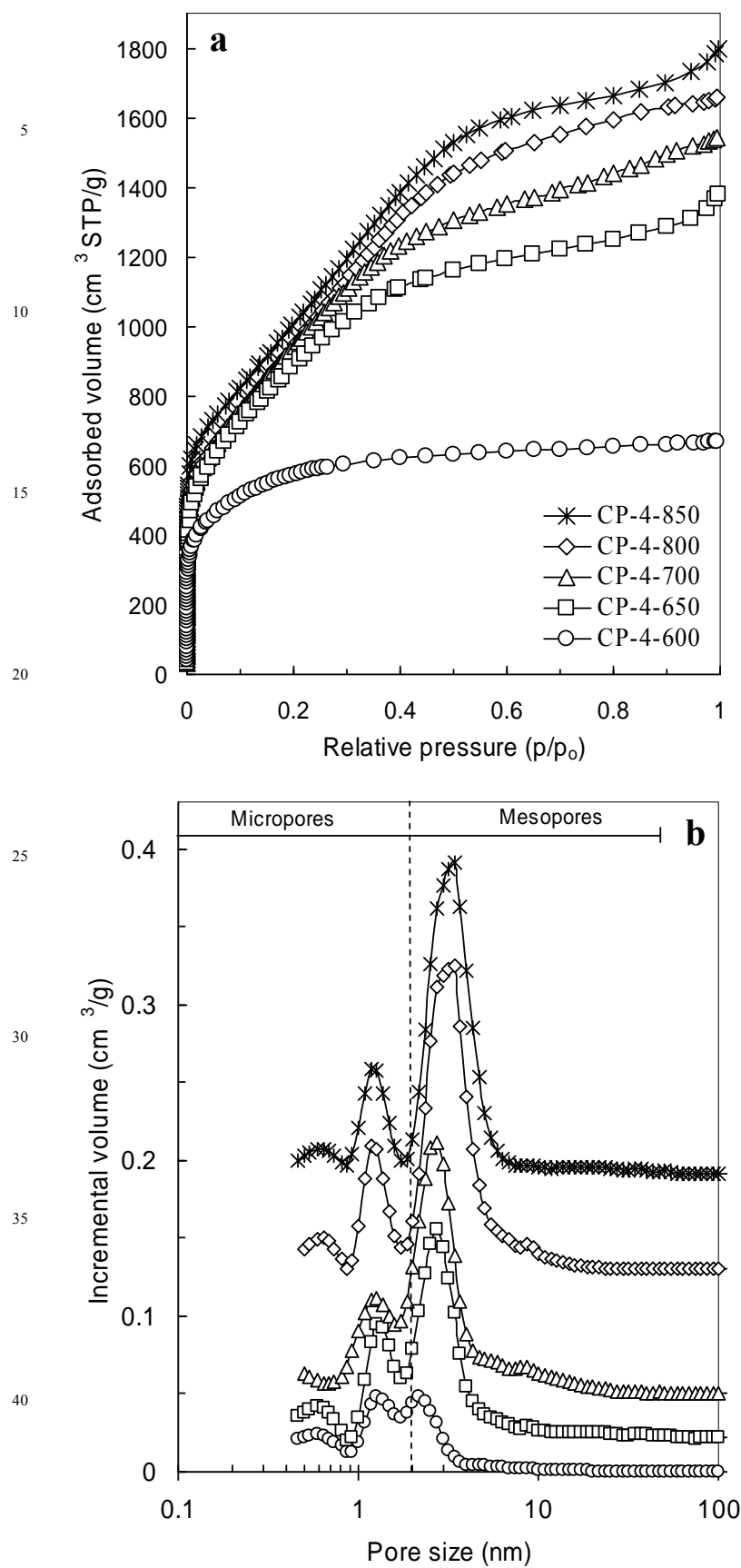

Fig. 2 a) Nitrogen sorption isotherms and b) Pore size distribution (PSD) curves of a set of activated carbons prepared at $\mathrm{KOH} /$ polypyrrole weight ratio of 4 and activation temperatures in the $600-850{ }^{\circ} \mathrm{C}$ range. For clarity, the PSD curves in (b) are off-set (y-axis) by 0.02, 0.05, 0.13 and $500.19 \mathrm{~cm}^{3} \mathrm{~g}^{-1}$ for CP-4-650, CP-4-700, CP-4-800 and CP-4-850 respectively. The PSD curves were obtained using a Non Local Density Functional Theory (NLDFT) model.

indicating the presence of mainly micropores and a smaller 55 proportion of small mesopores. On the other hand, the isotherms of samples activated at higher temperature (CP-4-650 to $\mathrm{CP}-4-850$ ) show an almost linear increase in adsorption in the relative pressure $(\mathrm{P} / \mathrm{Po})$ range of 0.1 to 0.4 indicating a shift from micropores to small mesopores at higher activating temperature. ${ }_{60}$ Indeed, PSD curves (Fig. 2b), which were obtained using a Non Local Density Functional Theory (NLDFT) model, show that the porosity is made up of two well-defined pore systems; (i) uniform supermicropores $(\sim 1.2 \mathrm{~nm})$ and (ii) small mesopores whose size gradually increases with the activation temperature from $2.2 \mathrm{~nm}$ ${ }_{65}\left(600{ }^{\circ} \mathrm{C}\right)$ to $3.4 \mathrm{~nm}\left(850{ }^{\circ} \mathrm{C}\right)$. Some carbons also possess a significant proportion of $0.6 \mathrm{~nm}$ pores. The textural parameters given in Table 1 indicate that most of the activated carbons have ultrahigh surface area, in the $3000-3500 \mathrm{~m}^{2} \mathrm{~g}^{-1}$ range. The surface area increases to a maximum for carbons activated at 700 70 and $800{ }^{\circ} \mathrm{C}$ then slightly decreases for the $850{ }^{\circ} \mathrm{C}$ sample. The pore volume of the carbons is unusually large (up to $\sim 2.6 \mathrm{~cm}^{3} \mathrm{~g}^{-1}$ for the samples activated at $800^{\circ} \mathrm{C}$ and $850{ }^{\circ} \mathrm{C}$ ). A large fraction of the surface area $(\sim 60 \%)$ and pore volume $(\sim 50 \%)$ arises from micropores as deduced by the t-plot method (Table 1). The 75 textural data suggest that the creation of new mesopores and their enlargement is favoured at higher activation temperature. This is most likely caused by increased gasification of the polypyrrole precursor by evolution of $\mathrm{CO}_{2}$ from decomposition of $\mathrm{K}_{2} \mathrm{CO}_{3}$ that is generated during the activation process. ${ }^{15}$

80 Carbon materials comprising of two pore systems, in the micropore and mesopore ranges, are highly desirable because of the large adsorption capacity in micropores and enhanced diffusion rates from mesopores. However, such micro/small mesopore carbon materials are difficult to prepare and have, so 85 far, only been been obtained via complex and multi-step procedures that combine hard or soft template techniques with physical or chemical activation steps. ${ }^{10 a, 16}$ To the best of our knowledge, to date, no one-step synthesis procedure has been reported for carbon materials with the micro/mesopore porosity 90 observed here. The ability to vary the porosity of the present activated carbons is further illustrated by the fact that changing the $\mathrm{KOH} / \mathrm{PPy}$ weight ratio from 4 to 2 (Supporting Figure S2) gives raise to carbons with porosity made up essentially of micropores (samples CP-2-650 and CP-2-700) and bimodal 95 porosity being observed for a high activation temperature sample (CP-2-800). The surface area (and pore volume) of carbons activated at 650 or $700{ }^{\circ} \mathrm{C}$ and $\mathrm{KOH} / \mathrm{PPy}$ weight ratio of 2 is lower than that of equivalent samples activated at $\mathrm{KOH} / \mathrm{PPy}$ ratio of 4 (Table 1). The differences in textural properties as the

100 amount of $\mathrm{KOH}$ decreases is due to diminution of the extent of gasification by the $\mathrm{CO}_{2}$ evolved in the decomposition of $\mathrm{K}_{2} \mathrm{CO}_{3}$. It is noteworthy that for any given activation temperature, carbons activated at $\mathrm{KOH} / \mathrm{PPy}$ ratio of 2 generally have a higher $\mathrm{N}$ content (Table 1).

105 When polypyrrole is subjected to simple carbonization (under a nitrogen environment) at $800{ }^{\circ} \mathrm{C}$, the $\mathrm{N}$ content decreases from $13.5 \mathrm{wt} \%$ to $11.7 \mathrm{wt} \%$ (Supporting Table S1). However, the present activated carbons contain much lower $\mathrm{N}$ content (Table 1 and Supporting Table S1). Furthermore, the N content decreases 110 with activation degree (i.e., increase of the activation temperature and/or the KOH/PPy ratio) as shown in Table 1 . The decrease in $\mathrm{N}$ content at greater activation occurs as a consequence of preferential oxidation of nitrogen functionalities during the activation process in a manner similar to that previously observed 115 for the activation of other types of nitrogen-containing precursors. ${ }^{17}$ Analysis of the activated carbons by FT-IR and XPS 
Table 1. Textural properties, $\mathrm{N}$ content, helium density, packing density and hydrogen uptake of polypyrrole-derived activated carbons

\begin{tabular}{|c|c|c|c|c|c|c|c|c|c|c|}
\hline \multirow[b]{2}{*}{ Sample $^{\mathrm{a}}$} & \multicolumn{5}{|c|}{ Textural properties } & \multirow[b]{2}{*}{$\begin{array}{c}\mathrm{N} \\
{[\mathrm{wt} \%]}\end{array}$} & \multicolumn{2}{|c|}{ Density } & \multicolumn{2}{|c|}{ Hydrogen storage } \\
\hline & $\begin{array}{c}\mathrm{S}_{\mathrm{BET}} \\
{\left[\mathrm{m}^{2} \mathrm{~g}^{-1}\right]}\end{array}$ & $\begin{array}{c}\mathrm{S}_{\text {micro }} \\
{\left[\mathrm{m}^{2} \mathrm{~g}^{-1}\right]^{\mathrm{b}}}\end{array}$ & $\begin{array}{c}\mathrm{V}_{\mathrm{p}} \\
{\left[\mathrm{cm}^{3} \mathrm{~g}^{-1}\right]^{\mathrm{c}}}\end{array}$ & $\begin{array}{c}\mathrm{V}_{\text {micro }} \\
{\left[\mathrm{cm}^{3} \mathrm{~g}^{-1}\right]^{\mathrm{d}}}\end{array}$ & $\begin{array}{l}\text { Pore size } \\
{[\mathrm{nm}]^{\mathrm{e}}}\end{array}$ & & $\begin{array}{l}\text { Helium } \\
{\left[\mathrm{g} \mathrm{cm}^{-3}\right]}\end{array}$ & $\begin{array}{l}\text { Packing } \\
{\left[\mathrm{g} \mathrm{cm}^{-3}\right]^{\mathrm{f}}}\end{array}$ & $\begin{array}{c}\mathrm{H}_{2} \text { uptake } \\
{[\mathrm{wt} \%]^{\mathrm{g}}}\end{array}$ & $\begin{array}{l}\text { Max. } \mathrm{H}_{2} \text { uptake } \\
{[\mathrm{wt} \%]^{\mathrm{h}}}\end{array}$ \\
\hline CP-4-600 & 2050 & 1670 & 1.03 & $0.74(72)$ & $1.3 / 2.2$ & 2.52 & 2.31 & 0.86 & $4.24(1.97)$ & 5.0 \\
\hline CP-4-650 & 3260 & 2080 & 2.13 & $1.03(48)$ & $1.3 / 2.7$ & 1.45 & 1.90 & 0.53 & $6.15(2.29)$ & 7.6 \\
\hline CP-4-700 & 3480 & 2190 & 2.39 & $1.18(49)$ & $1.3 / 2.9$ & 0.72 & 1.75 & 0.35 & $6.71(2.40)$ & 8.3 \\
\hline CP-4-800 & 3450 & 1910 & 2.57 & $1.22(47)$ & $1.2 / 3.2$ & 0.47 & 1.75 & 0.31 & $7.03(2.55)$ & 8.7 \\
\hline CP-4-850 & 3360 & 1850 & 2.62 & $1.22(46)$ & $1.2 / 3.4$ & 0.32 & 2.31 & 0.30 & $6.73(2.56)$ & 8.2 \\
\hline CP-2-650 & 2520 & 2420 & 1.25 & $1.08(86)$ & 1.3 & 4.05 & 1.53 & 0.67 & $5.19(2.34)$ & 6.1 \\
\hline CP-2-700 & 2940 & 2660 & 1.37 & $1.14(83)$ & $1.3 / 2.0$ & 2.14 & 1.78 & 0.46 & $6.13(2.63)$ & 7.3 \\
\hline CP-2-800 & 3410 & 2530 & 1.94 & $1.21(62)$ & $1.2 / 2.5$ & 0.78 & 1.72 & 0.28 & $6.54(2.51)$ & 8.0 \\
\hline
\end{tabular}

${ }^{a}$ Porous carbon samples are denoted as CP- $x-y$, where $x$ is KOH/popypyrrole weight ratio and $y$ the activation temperature (in ${ }^{\circ} \mathrm{C}$ ); ${ }^{b} \mathrm{Determined}$ by the $t$-plot method. ${ }^{\mathrm{c}}$ Total pore volume at relative pressure $(\mathrm{P} / \mathrm{Po}) \sim 0.99 .{ }^{\mathrm{d}}$ Determined by the $t$-plot method; the values in parentheses are the percentage of micropore volume as a function of total pore volume. ${ }^{\mathrm{e}}$ Maxima of the pore size distribution (PSD) calculated using the NLDFT model, assuming slitshaped pores. ${ }^{\mathrm{f}}$ Packing density calculated after pressing sample in a mould at $7 \mathrm{MPa} .{ }^{\mathrm{g}} \mathrm{Hydrogen}$ uptake capacity at $-196{ }^{\circ} \mathrm{C}$ and 20 bar; the uptake at 1 bar is shown in parentheses. he Estimated maximum hydrogen uptake capacity at $-196^{\circ} \mathrm{C}$ derived from Langmuir simulation plots.

(Supporting Figure S3) confirmed the presence of a variety of nitrogen functionalities (N-pyrrolic or N-pyridone). Therefore, the present polypyrrole-derived activated carbons contain basic nitrogen groups, which may play an important role in the capture 5 of acidic gases (i. e., $\mathrm{CO}_{2}$ ), ${ }^{17 a}$ energy storage in electrochemical capacitors ${ }^{18}$ or hydrogen adsorption. ${ }^{14 e, 19}$ Zhao et al. showed that nitrogen and oxygen groups have a detrimental effect on the maximum hydrogen uptake. ${ }^{19}$ More recently, Xia and co-workers proved experimentally that $\mathrm{N}$-doping is beneficial at low 10 hydrogen uptake but detrimental at higher uptake, in agreement with theoretical studies. ${ }^{14 \mathrm{~d}}$ However, it is worth noting that the $\mathrm{N}$ content of the present activated carbons is lower than that in previous studies. ${ }^{14 d, 19}$ The oxygen and hydrogen content of the activated carbons decrease at higher activation levels (Supporting

15 Table S1). Raman spectra (Supporting Figure S4) confirmed that the polypyrrole-derived activated carbons have a certain level of graphitic ordering that decreases at higher activation levels.

The potential of the activated carbons as hydrogen stores was investigated at $-196{ }^{\circ} \mathrm{C}$ over the pressure range $0-20$ bar using a 20 gravimetric method. For buoyancy corrections, densities of 0.04 and $1.72-2.31 \mathrm{~g} \mathrm{~cm}^{-3}$ were applied for adsorbed hydrogen ${ }^{7}$ and activated carbons respectively. Figure $3 \mathrm{a}$ shows the total hydrogen uptake isotherms for the various activated carbons. The hydrogen uptake isotherms are completely reversible and exhibit 25 no saturation in the $0-20$ bar pressure range. This suggests that higher hydrogen uptakes can be obtained if the pressure is increased over 20 bar. Indeed, an estimated maximum hydrogen uptake capacity can be computed by fitting the experimental data using the Langmuir model. ${ }^{7 \mathrm{a}, 20}$ The storage capacity at 20 and 1 30 bar along with the computed maximum hydrogen uptake are given in Table 1. At 1 and 20 bar, the activated carbons exhibit excellent hydrogen uptake capacity of up to 2.63 and $7.03 \mathrm{wt} \%$ respectively (Table 1 ). The observed storage capacity is remarkable in the context of previous studies where one-step 35 activated carbons normally achieve hydrogen uptake (at $-196{ }^{\circ} \mathrm{C}$ and $20 \mathrm{bar}$ ) in the range $3.0-5.6 \mathrm{wt} \%{ }^{4}$ Regarding the estimated likely maximum hydrogen uptake, values of $7.3-8.7 \mathrm{wt} \%$ are computed for all the carbons except for those samples that were activated under mildest conditions
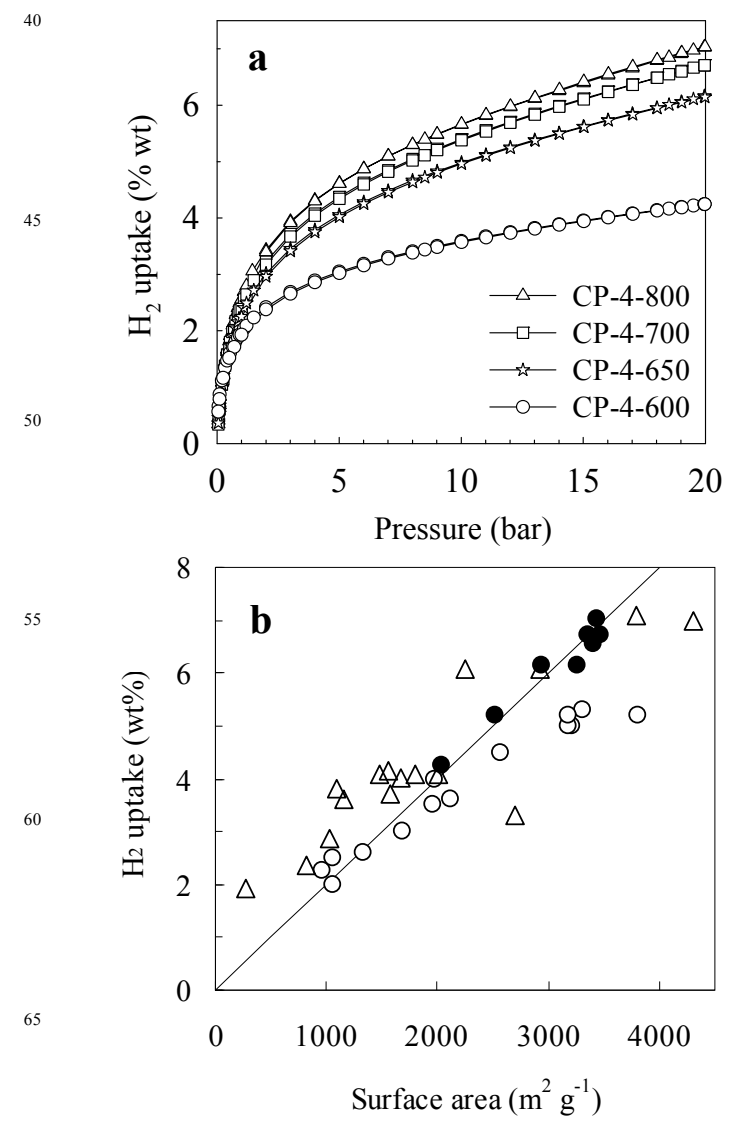

Fig. 3 a) Hydrogen sorption isotherms at $-196^{\circ} \mathrm{C}$ of a set of activated 70 carbons prepared at $\mathrm{KOH} /$ polypyrrole weight ratio of 4 and activation temperatures in the $600-850^{\circ} \mathrm{C}$ range, b) a comparison of the hydrogen uptake capacity (measured at $-196^{\circ} \mathrm{C}$ and 20 bar) vs. surface area for onestep activated carbons and MOFs: this work $(\bullet)$ and data reported in the literature for activated carbons [4] (०) and MOFs [23] ( $\Delta$ ). The solid line 75 corresponds to the Chahine rule.

and thus exhibited the lowest porosity (i.e., CP-4-600 and CP-2- 650). The hydrogen uptake achieved (up to $7.03 \mathrm{wt} \%$ ) is 
amongst the highest ever reported for carbons and compares favourably with other benchmark porous materials. ${ }^{2 b, 4,5,7,11}$ The hydrogen uptake appears to be closely dependent on the textural properties, and generally increases at higher surface area. The 5 lowest surface area sample (CP-4-600) exhibits the smallest uptake capacity. It is however noticeable that sample CP-4-800 has a higher hydrogen uptake than CP-4-700 and CP-2-800 despite a similar surface area. The samples have similar $\mathrm{N}$ content but differ in the amount of oxygen, with CP-4-800 having 10 the least. It is therefore likely that although the textural properties are the greatest determinant of hydrogen uptake, higher amounts of oxygen are detrimental. Observation of the comparatively detrimental effects of a high oxygen content would be consistent with the work of Zhao and co-workers, who observed a decrease 15 in the adsorbate-adsorbent interactions with increasing oxygen concentrations in activated carbons. ${ }^{19}$

It is interesting to note that although a significant proportion of the porosity of the present activated carbons is in mesopores that are considered less efficient for hydrogen storage, ${ }^{5,7,14}$ the 20 materials still exhibit impressive hydrogen storage due to their ultrahigh surface area. However, it is noteworthy that the hydrogen uptake of the activated carbons is in line with the Chahine rule, ${ }^{21}$ which stipulates an uptake of $10 \mu \mathrm{mol} \mathrm{H}_{2}$ per $\mathrm{m}^{2}$ (represented by the solid line in Figure 3b). Therefore, the present ${ }_{25}$ samples do not outperform the Chahine rule, which may be a consequence of the presence of a large number of mesopores. Our previous work shows that the hydrogen uptake of carbons that are predominantly microporous (and with few or no mesopores) generally tends to outperform the Chahine rule. ${ }^{7,11}$ A linear 30 dependence, similar to that in Figure $3 \mathrm{~b}$, is observed between the micropore volume of the activated carbons and their hydrogen uptake (Supporting Figure S5).

To date, the highest values reported for hydrogen storage in carbon materials (at $-196{ }^{\circ} \mathrm{C}$ and 20 bar) are $6.84 \mathrm{wt} \%$ (estimated

35 maximum $=8.24 \mathrm{wt} \%$ ) for a $\mathrm{KOH}$-activated mesoporous nitrogen-doped carbon, ${ }^{20} 6.9 \mathrm{wt} \%$ (estimated maximum $=8.33$ $\mathrm{wt}^{\mathrm{O}} \%$ ) achieved by Yang et al. with a zeolite-like carbon material ${ }^{7 \mathrm{a}}$ and $7.08 \mathrm{wt} \%$ for a doubly activated carbon. ${ }^{13}$ At $-196{ }^{\circ} \mathrm{C}$ and 1 bar, values of up to $3.0 \mathrm{wt} \%$ have been obtained for templated 40 carbons. ${ }^{7,811,22}$ These previous reports involved templated synthesis, where the carbon yield is low or multi-step activation, which therefore highlights the attraction of the present polypyrrole-derived activated carbons which are prepared via a simple and high yield procedure. The superior performance of the ${ }_{45}$ present activated carbons is clearly illustrated in Figure 3b, where they are compared with various activated carbon and metal organic framework (MOF) materials. ${ }^{4,23}$ It is clear that the present carbons outperform previously reported comparable carbonaceous materials and have uptake similar to that of the best ${ }_{50}$ MOFs. A further attraction of the present carbons is that due to their good carbon yield, they exhibit reasonably high packing density (Table 1), which is an important variable in determining volumetric hydrogen uptake. (We note that the packing density values given in Table 1 are conservative as they were obtained 55 after compaction at relatively low $(7 \mathrm{MPa})$ pressure compared to previous studies). ${ }^{13,24,25}$ The packing density values given in Table 1 lead to volumetric capacities typically in the range $20-$ $37 \mathrm{~g} \mathrm{H}_{2} \mathrm{~L}^{-1}$ at 20 bar, and $25-43 \mathrm{~g} \mathrm{H}_{2} \mathrm{~L}^{-1}$ at the estimated maximum capacity. These volumetric capacity values are 60 comparable or superior to those of other activated carbons and MOFs. ${ }^{1 b, 4 b, 24,25}$ Furthermore, given that the packing density of the carbons can be increased by compaction at higher pressure to at least $0.6 \mathrm{~g} \mathrm{~cm}^{-3}$ without much change in porosity, ${ }^{24 b, 25}$ it is possible to envisage volumetric density of up to $42 \mathrm{~g} \mathrm{H}_{2} \cdot \mathrm{L}^{-1}$ at 20 ${ }_{65}$ bar and even higher (i.e., $50 \mathrm{~g} \mathrm{H}_{2} \mathrm{~L}^{-1}$ ) at the estimated maximum hydrogen uptake capacity for carbons activated at between 650 and $800{ }^{\circ} \mathrm{C}$ and $\mathrm{KOH} / \mathrm{PPy}$ ratio of 4 . The high porosity of the present carbons is not at the detriment of packing density, which means that the samples combine both a superior hydrogen 70 gravimetric uptake and impressive volumetric density.

Our hydrogen uptake data indicate that although pores of size $0.7 \mathrm{~nm}$ have been shown to be the most effective in hydrogen storage, ${ }^{5,7,14}$ slightly larger pores can also store significant amounts of hydrogen. The hydrogen uptake can therefore be high 75 if there is a large pore volume and surface area of larger micropores and small mesopores. Some of the present PPyderived carbons have not only high surface area but also very high pore volume (up to $2.6 \mathrm{~cm}^{3} \mathrm{~g}^{-1}$ ) - and it is these carbons that show very high hydrogen uptake. We are not aware of activated ${ }_{80}$ carbons that simultaneously show such a high surface area and pore volume associated with micropores and small mesopores. Most high surface area activated carbons have pore volume of less than $2 \mathrm{~cm}^{3} \mathrm{~g}^{-1} \cdot{ }^{13,20,25-27} \mathrm{We}$ are aware of one example of a high pore volume $\left(2.12 \mathrm{~cm}^{3} \mathrm{~g}^{-1}\right)$ activated carbon - which also ${ }_{85}$ had a high hydrogen uptake and wherein it was argued that small mesopores, as well as the micropores, play an important part in the hydrogen adsorption under high pressure. ${ }^{20}$ We therefore believe that the combination of three factors; bimodal pore size of micropores and small mesopores, high surface area and high pore 90 volume that are unique to the present carbons (and in particular the high pore volume) contribute to the enhanced hydrogen uptake especially at higher $(20 \mathrm{bar})$ pressure.

\section{Conclusions}

In summary, we have shown for the first time a facile procedure 95 for the synthesis of carbon materials with ultrahigh surface area $\left(3000-3500 \mathrm{~m}^{2} \mathrm{~g}^{-1}\right.$ ) and pore volume (up to $\sim 2.6 \mathrm{~cm}^{3} \mathrm{~g}^{-1}$ ) comprising of two pore systems; one pore size system in the micropore range $(\sim 1.2 \mathrm{~nm})$ and the other in the mesopore range $(2.2-3.4 \mathrm{~nm})$. The choice of polypyrrole as the carbon precursor 100 is the key to obtaining, via chemical activation with $\mathrm{KOH}$, porous carbons with outstanding textural properties. The activated carbon materials exhibit excellent hydrogen uptake of up to 7.03 $\mathrm{wt} \%$ (at $-196{ }^{\circ} \mathrm{C}$ and $20 \mathrm{bar}$ ). An estimated maximum uptake of 8.7 wt $\%$ is computed using Langmuir plots. ${ }^{[7,20]}$ The gravimetric 105 hydrogen uptake translates to attractive volumetric density of up to $37 \mathrm{~g} \mathrm{H}_{2} \mathrm{~L}^{-1}$ at 20 bar. An estimated volumetric uptake of $43 \mathrm{~g}$ $\mathrm{H}_{2} \mathrm{~L}^{-1}$ is computed from Langmuir plots. Therefore the carbons exhibit both superior gravimetric and excellent volumetric capacity due to the fact that their high porosity is not at the 110 detriment of packing density. The hydrogen uptake of the present carbons is the highest ever reported for one-step activated carbons and amongst the best for any porous material. 


\section{Acknowledgments}

M. S. acknowledges the assistance of the Spanish MICINN for the award of a postdoctoral mobility contract. The authors acknowledge J. L. Baldonedo (UCM) for the TEM and HRTEM 5 images.

\section{Notes and references}

${ }^{a}$ Instituto Nacional del Carbón (CSIC), P.O. Box 73, 33080 Oviedo, Spain. Fax: +34 9852976 62; Tel: +34 9851189 70; E-mail: abefu@incar.csic.es (A. B. Fuertes)

$10{ }^{b}$ School of Chemistry, University of Nottingham, University Park, NG7 2RD Nottingham, U.K.. Fax: +44 (0) 115951 3562; Tel: +44 (0) 115846 6174; E-mail: r.mokaya@nottingham.ac.uk (R.Mokaya)

$\uparrow$ Electronic Supplementary Information (ESI) available: Elemental composition of polypyrrole-derived activated carbons, TGA of

15 polypyrrole, comparison of nitrogen sorption isotherms and pore size distribution curves for carbon samples activated at KOH/PPy weight ratio of 2 or 4 and various temperatures, Infra-red (IR) and N 1s core-level spectra of CP-4-700, Raman spectra for carbon samples activated at $\mathrm{KOH} / \mathrm{PPy}$ weight ratio of 4 and various temperatures, and correlation

20 between hydrogen storage capacity and micropore volume of the activated carbons. See DOI: 10.1039/b000000x/

1 (a) A. W. C van den Berg and C. O. Arean, Chem. Commun., 2008, 6, 668; (b) D. Zhao, D. Yuan and H. C. Zhou, Energy Environ. Sci., 2008, 1, 222; (c) DOE Hydrogen Program, FY 2004 Progress Report. 25 <http://www.eere.energy.gov/hydrogenandfuelcells/pdfs/annual04/iii storage_intro.pdf $>$. 179-181 (2004).

2 (a) Y. H. Hu and L. Zhang, Adv. Mater., 2010, 22, E117-E130; (b) M. Hirscher, B. Panella and B. Schmitz, Microporous Mesoporous Mater., 2010, 129, 335.

303 R. E. Morris and P. Wheatley, Angew. Chem. Int. Ed., 2008, 47, 4966.

4 (a) B. Panella, M. Hirscher and S. Roth, Carbon, 2005, 43, 2209; (b) M. Jordá-Beneyto, F. Suárez-García, D. Lozano-Castelló, D. CazorlaAmorós and A. Linares-Solano, Carbon, 2007, 45, 293; (c) K. M.

35 Thomas, Catal. Today, 2007, 120, 389; (d) M. Sevilla, A. B. Fuertes and R. Mokaya, Energy Environ. Sci., 2011, 4, 1400.

5 Y. Gogotsi, C. Porteta, S. Osswald, J. M. Simmons, T. Yildirim, G. Laudisio and J. E. Fischer, Int. J. Hydrogen Energy, 2009, 34, 6314.

6 J. Dong, X. Wang, H. Xu, Q. Zhao and J. Li, Int. J. Hydrogen $40 \quad$ Energy, 2007, 32, 4998.

7 (a) Z. Yang, Y. Xia and R. Mokaya, J. Am. Chem. Soc., 2007, 129, 1673; (b) A. Pacula and R. Mokaya, J. Phys. Chem. C, 2008, 112, 2764; (c) N. Alam and R. Mokaya, Energy Environ. Sci., 2010, 3, 1773 .

45 8. (a) Y. Gogotsi, R. K. Dash, G. Yushin, T. Yildirim, G. Laudisio and J. E. Fischer, J. Am. Chem. Soc., 2005, 127, 16006; (b) G. Yushin, R. Dash, J. Jagiello, J. E. Fischer, Y. Gogotsi, Adv. Funct. Mater., 2006, 16, 2288.

9. A. Nikitin and Y. Gogotsi, in Encyclopedia of Nanoscience and

50 Nanotechnology, Vol. 10: Nanostructured carbide-derived carbons (Ed.: H.S. Nalwa) Pages 1-22, 2004.

10 (a) K. Xia, Q. Gao, C. Wu, S. Song and M. Ruan, Carbon, 2007, 45, 1989; (b) K. Xia, Q. Gao, S. Song, C. Wu, J. Jiang, J. Hu and L. Gao, Int. J. Hydrogen Energy, 2008, 33, 116; (c) M. Choi and R. Ryoo, J.

55 Mater. Chem., 2007, 17, 4204; (d) M. Armandi, B. Bonelli, E. I. Karaindrou, C. Otero Area and E. Garrone, Catal. Today, 2008, 138, 244.

11 (a) M. Sevilla, N. Alam and R. Mokaya, J. Phys. Chem. C, 2010, 114, 11314; (b) M. Sevilla, R. Foulston and R. Mokaya, Energy 60 Environ. Sci., 2010, 3, 223; (c) M. Sevilla and R. Mokaya, J. Mater. Chem. 2011, 21, 4727.

12 (a) S. J. Allen, L. Whitten and G. Mckay, Dev. Chem. Eng. Mineral Process., 1998, 6, 231; (b) J. A. Maciá-Agulló, B. C. Moore, D. Cazorla-Amorós and A. Linares-Solano, Carbon, 2004, 42, 1367; (c)

65 M. Wu, Q. Zha, J. Qiu, Y. Guo, H. Shang and A. Yuan, Carbon, 2004, 42, 205; d) D. Lozano-Castelló, D. Cazorla-Amorós and A. Linares-Solano, Fuel Process. Technol., 2002, 77-78, 325.
13 H. Wang, Q. Gao and J. Hu, J. Am. Chem. Soc., 2009, 131, 7016.

14 (a) N. Texier-Mandoki, J. Dentzer, T. Piquero, S. Saadallah, P. David and C. Vix-Guterl, Carbon, 2004, 42, 2744; (b) S. K. Bhatia, A. L. Myers, Langmuir 2006, 22, 1688; (c) I. Cabria, M. J. López, J. A. Alonso, Carbon 2007, 45, 2649; (d) Y. Xia, G. S. Walker, D. M. Grant, R. Mokaya, J. Am. Chem. Soc. 2009, 131, 16493.

15 (a) P. Ehrburger, A. Addoun, F. Addoun and J. B. Donnet, Fuel, 1986, 65, 1447; (b) M. J. Illán-Gómez, A. García-García, C. SalinasMartínez de Lecea and A. Linares-Solano, Energy Fuel, 1996, 10, 1108; (c) H. Teng and L-Y. Hsu, Ind. Eng. Chem. Res., 1999, 38 2947.

16 (a) M. Choi, R. Ryoo, J. Mater. Chem. 2007, 17, 4204; (b) J. Gorka, A. Zawislak, J. Choma, M. Jaroniec, Carbon 2008, 46, 1159.

17 (a) T. C. Drage, A. Arenillas, K. M. Smith, C. Pevida, S. Piipo and C. E. Snape, Fuel, 2007, 86, 22; (b) H. Wang, Q. Gao and J. Hu, Microporous Mesoporous Mater., 2010, 131, 89; (c) L. Zhao, L-Z Fan, M-Q. Zhou, H. Guan, S. Qiao, M. Antonietti and M-M. Titirici, Adv. Mater., 2010, 22, 5202.

18 (a) D. Hulicova-Jurcakova, M. Seredych, G. Q. Lu and T. J. Bandosz, Adv. Funct. Mater., 2009, 19, 438; (b) R. Mysyk, E. RaymundoPiñero, M. Anouti, D. Lemordant and F. Béguin, Electrochem. Commun., 2010, 12, 414.

9019 X. B. Zhao, B. Xiao, A. J. Fletcher and K. M. Thomas, J. Phys. Chem. B, 2005, 109, 8880 .

20 Z. Zheng, Q. Gao and J. Jiang, Carbon, 2010, 48, 2968.

21 E. Poirier, R. Chahine and T. K. Bose, Int. J. Hydrogen Energy, 2001, 26, 831 .

9522 B. Liu, H. Shioyama, T. Akita and Q. Xu, J. Am. Chem. Soc., 2008, 130, 5390.

23 K. M. Thomas, Dalton Trans., 2009, 9, 1487.

24 (a) P. X. Hou, H. Orikasa, H. Itoi, H. Nishihara and T. Kyotani, Carbon, 2007, 45, 2011; (b) J. Alcañiz-Monge, G. Trautwein, M

100 Pérez-Cadenas and M. C. Román-Martínez, Microporous Mesoporous Mater., 2009, 126, 291.

25 J. Juan-Juan, J. P. Marco-Lozar, F. Suárez-García, D. CazorlaAmorós and A. Linares-Solano, Carbon, 2010, 48, 2906.

26 J. Burress, M. Kraus, M. Beckner, R. Cepel, G. Suppes, C. Wexler and P. Pfeifer, Nanotechnology, 2009, 20, 204026.

27 F. Cheng, J. Liang, J. Zhao, Z. L. Tao and J. Chen, Chem. Mater. 2008, 20, 1889. 